\title{
Drought Risk Assessment based on PDSI in the Daqinghe Watershed, North China
}

\author{
Shaohua Liu ${ }^{1, a}$, Huiyong Huang ${ }^{1}$, Gang $\mathrm{Hu}^{1}$, Hui Wan ${ }^{1}$, Yongyan $\mathrm{Wu}^{1}$, Yibo Yan ${ }^{1}$, Sidong Zeng ${ }^{1}$ \\ ${ }^{1}$ Changjiang Institute of Survey, Planning, Design and Research, 430010, Wuhan, China
}

\begin{abstract}
Drought is a worldwide natural disaster and has become an obstacle to the socio-economic development of the Daqinghe watershed in North China, the drought risk of which is analyzed in this study. PDSI is established and validated by the SPI, SRI, SMI, and agriculture drought-affect area in Baoding, a city in Daqinghe watershed. The result shows that PDSI performs well in describing the drought evolution, especially in the monthly scale. Then, the drought risk is assessed combining the drought hazard derived from PDSI with the exposed vulnerabilities consisting of the population, Gross Domestic Product (GDP), cropland area, and vegetation area. It indicates that the subwatersheds with high drought risk mainly concentrate in the downstream plain area.
\end{abstract}

\section{Introduction}

Drought is one of the most prevalent natural disaster, it occurs not only in arid regions but also in humid regions and has a huge impact on the socio-economy and ecological system [1-5]. IPCC's report (2012) showed that drought will intensify in the 21 st century in many regions around world. Meanwhile, several researches have pointed out that drought has an increasing trend in the recent half century over the mainland of China, especially the north China, and caused enormous socioeconomic loss [6-9]. Therefore, the drought assessment has already became an important subject, which attracted the attention of hydrologists, ecologists, meteorologists, and agricultural scientists $[10,11]$.

However, the researchers from different disciplines give various definitions of drought such as meteorological drought, hydrological drought, and agricultural drought [12-14]. Accordingly, diverse indices have been developed to drought assessment in recent decades [15]. The climatic factors are often used to develop the meteorological drought indices, the most widely used one is the standardized precipitation index (SPI) [16] depended only on the precipitation. In contrast, the primary factors of hydrological and agricultural drought indices are the runoff and soil moisture, which are applied into the standard runoff index (SRI) [17] and the soil moisture index (SMI) [18], respectively. Nevertheless, the climatic, hydrological, and soil factors originated from stations are significantly affected by the spatial heterogeneity, which reveals that the drought assessment on the station scale may be more uncertain than that of the region scale [19]. Additionally, drought is an abnormal water deficiency of hydrological cycle, the drought indices derived from the single or several related factors cannot demonstrate the drought condition comprehensively. Among plenty of drought indices [15], Palmer Drought Severity Index (PDSI) is a regional index derived from the integrated hydrological cycle [20], and has been widely applied into investigating the spatial and temporal drought characteristics [21,22], exploring the periodic behavior of droughts [23], drought assessment over large areas [24], and drought forecasting [25].

As a process-based drought index, PDSI incorporats the antecedent precipitation, moisture supply and demand into hydrological cycle and the soil moisture is calculated by a two-layer bucket-type model [20], which is the essential fundament to support the PDSI. Additionally, IPCC special report (2012) defined the disaster risk as the combination of the disaster hazard and the exposed vulnerabilities. Accordingly, the drought risk derives from not only the drought hazard but also the exposed vulnerabilities of human society and ecological system [26]. On the one hand, drought hazard represents the potential drought risk caused by the external environment, it can be obtained from PDSI. On the other hand, the exposed vulnerabilities refer to the inability to withstand the effects of drought hazard, the population, Gross Domestic Product (GDP), areas of cropland and vegetation (without cropland) are applied into this study. Among the four factors, the former three factors stand for the socio-economic aspects, and the area of vegetation represents the ecological aspect.

In following sections of this study, the Daqinghe watershed is selected as the study domain in Section 2.1, and the frame of drought risk assessment are introduced in Section 2.2. Accordingly, drought risk assessment of Daqinghe watershed is analyzed in Section 3. Then the conclusions are given in Sections 4.

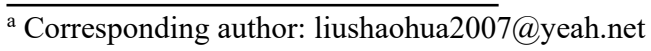




\section{Materials and methods}

\subsection{Study area}

Daqinghe watershed is a typical semi-arid watershed located in the North China, it is a major grain-producing region with the area of about $3.7 \times 104 \mathrm{~km}^{2}$ (Figure.1). The watershed is one of the highest population density region with huge development potential and next to the Beijing. The average annual precipitation of Daqinghe watershed is about $480 \mathrm{~mm}$ from 1991 to 2010, and most of precipitation concentrates in flood season (July to September) in Daqinghe. The distribution of precipitation is uneven and inconsistent with the distribution of socio-economy, which is an obstacle to regional development. Moreover, the rapid socioeconomic development contributes to the increase of the water stress and groundwater overexploitation have become a serious issue in the Daqinghe watershed recent decades.

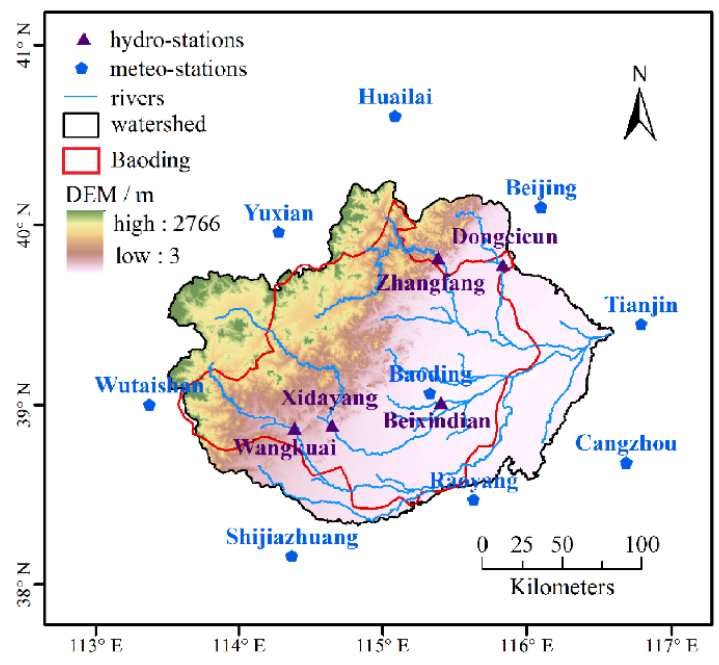

Figure 1. Topographic map of Daqinghe watershed and location of hydro-meteorological stations.

\subsection{Methods}

PDSI is a commonly used drought evaluation index, which has been described particully by Palmer (1965). The drought risk derives from vulnerabilities of the socio-economy and ecological system to drought hazard. For socio-economy the population, GDP, and cropland are the major indices to measure the level of socioeconomic development [14]. Meanwhile, the ecological system is so diversity and complicated that there is no adequate index to represent the ecological condition overall. However, the vegetation system is the fundamental component of ecological system, and vegetation area can be observed and quantified conveniently. Therefore, the population, GDP, cropland area, and vegetation area (without cropland, similarly hereinafter) for per square kilometer are taken as the vulnerable indices to drought hazard. Then the drought risk can be represented as follows:

$$
\begin{gathered}
R_{i}=H_{i} \times\left(W_{p} \times P_{i}+W_{g} \times G_{i}+W_{c} \times C_{i}+W_{v} \times V_{i}\right) \\
H_{i}=W^{1} \times f^{1}{ }_{i}+W^{2} \times f^{2}{ }_{i}+W^{3} \times f^{3}{ }_{i}+W^{4}{ }_{i} \times f^{4_{i}}
\end{gathered}
$$

Where $i$ is the serial number of 52 subwatersheds; $R$ represents the drought risk; $H$ represents the drought hazard index; the $f^{1}, f^{2}{ }_{i}, f^{3}{ }_{i}$, and $f^{4}{ }_{i}$ are frequencies of mild drought, moderate drought, severe drought, and extreme drought; the $w_{i}^{1}, w_{i}{ }_{i}, w_{i}^{3}$, and $w^{4}{ }_{i}$ are corresponding weights of drought frequency and are setted to $1,2,3$, and 4, respectively; the $P, G, C$, and $V$ represent vulnerable indices of population, GDP, cropland area, and vegetation area, respectively. Since the dimensions and magnitude of the exposed elements are different and incomparable, thus the vulnerable indices should be translated into dimensionless variation as follows:

$$
\begin{gathered}
P_{i}=\text { pop }_{i} / \text { pop max } \\
G_{i}=g d p_{i} / g d p_{\max } \\
C_{i}=\operatorname{crop}_{i} / \operatorname{crop}_{\max } \\
V_{i}=\operatorname{veg}_{i} / \operatorname{veg}_{\max }
\end{gathered}
$$

Where the $\operatorname{pop}_{i}, g d p_{i}, \operatorname{crop}_{i}$, and $v \mathrm{~g}_{i}$ are the population, GDP, cropland area, and vegetation area per square kilometer of $i$ th subwatershed; and pop $\max$, crop $_{\max }, a g r_{\max }$, and $v e g_{\max }$ are the maximum population, GDP, cropland area, and vegetation area per square kilometer of the subwatershed, respectively. $w_{p}, w_{g}, w_{c}$, and $w_{v}$ are corresponding weights of vulnerable index. However, the drought impacts on different exposed vulnerabilities, especially of the ecological system, are significantly complicated and significantly different. Thus, it's so hard to assign weights for the four vulnerable indices that the weights $\left(w_{p}, w_{g}, w_{c}\right.$, and $\left.w_{v}\right)$ are equally set to 0.25 in this study.

\section{Results}

\subsection{PDSI validation}

As the most sensitive sector to the drought hazard, agriculture is significantly impacted by the drought in the Daqinghe watershed. According to previous research, there is a logarithmic relationship between the agricultural drought-affected area and drought magnitude [11, 27]. Thus, the logarithmic indices of agricultural drought-affected areas (LIADAA) is calculated via the logarithmic transformation of agricultural drought-affected areas. Baoding with the area accounting for more than $60 \%$ of the watershed is located in the central part of the watershed. Then, according to the agricultural drought-affected area series (1994-2010) derived from Economic Statistical Yearbook of Baoding (1995-2011), the LIADAA, SRI, and SMI are calculated in order to validate the PDSI in Baoding (Figure.2), and the correlations between annual PDSI/SPI/SRI/SMI and LIADAA are showed in Figure.2. The results show that all of PDSI, SPI, SRI, 
and SMI are significantly consistent with the LIADAA overall at the annual scale. Furthermore, the monthly PDSI, SPI, SRI, and SMI are illustrated in Figure.3, which displays that there is a markedly difference among the four indices at monthly scale. The frequent alternations of wet-drought derived from monthly SPI and SRI don't take the cumulative effect of drought, so they cannot describe the big drought (1998-2003) in North China [11]. Although the SMI can presents the cumulative effect of drought since the soil water storage capacity, the drought obtained from the SMI evolved steeply. However, the onset and end of drought are gradual processes $[10,28]$, which reveals that PDSI is more reasonable to describe the drought evolution at monthly scale. Additionally, PDSI is an integrated index derived from the anomaly of the hydrological cycle. Consequently, the process-based PDSI is an adequate drought index to the Daqinghe watershed.

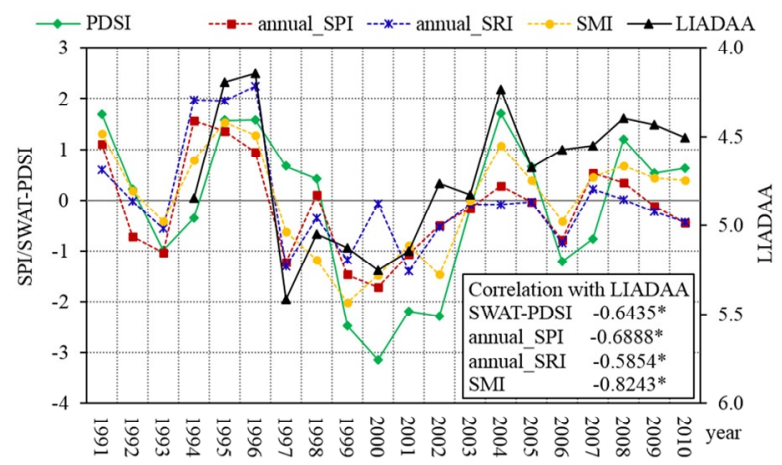

Figure.2 Comparisons of annual PDSI, SPI and LIADAA in Baoding. The annual PDSI and SMI are the average value of

12 calendar monthly PDSI and SMI; the annual_SPI and annual_SRI are the output of SPI and SRI at annual scale, respectively. The correlation with * represent the correlation is significant at a level of 0.05 .

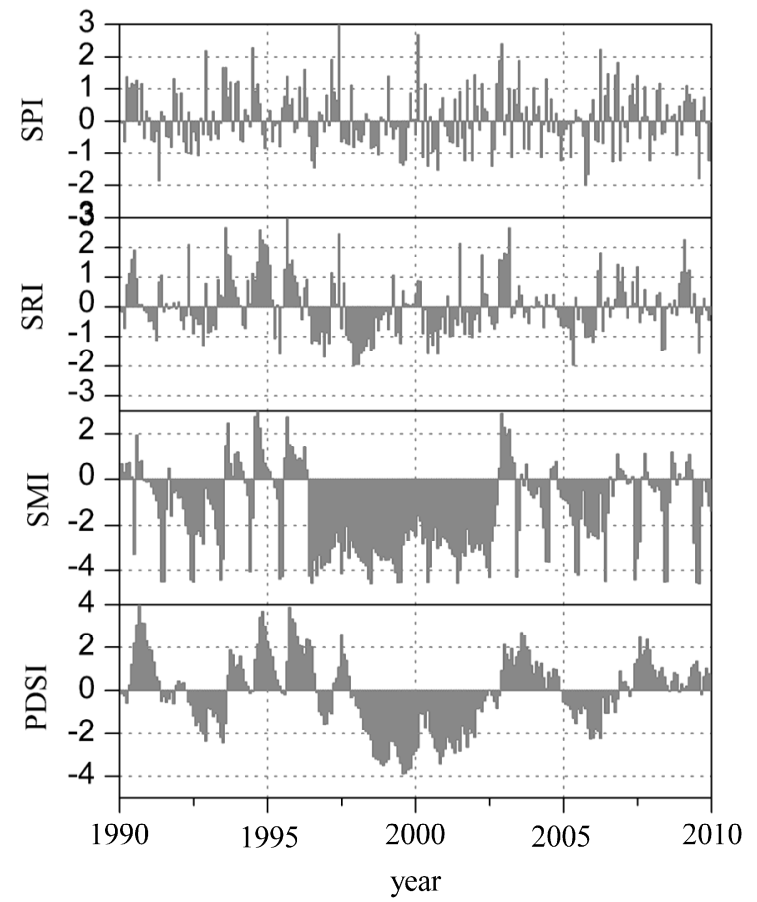

Figure.3 Comparisons of monthly PDSI, SPI, SRI, and SMI from 1991 to 2010 in the Daqinghe watershed.

\subsection{Drought risk assessment}

Based on the PDSI of the Daqinghe watershed during 1991-2010, drought hazard has been calculated. The result demonstrates that the high drought hazard subwatersheds concentrate in the downstream plain area of the watershed, especially of the middle plain. Meanwhile, the exposed vulnerabilities of population, GDP, cropland area, and vegetation area are illustrated in Figure.4b-4e. It can be seen that the distribution of GDP, population, and cropland area are consistent with the distribution of drought hazard. The drought hazard is higher, the socio-economic vulnerabilities are bigger, which promotes the drought risk. The vegetation area demonstrates an inverse distribution in comparison with the drought hazard distribution, and it is advantageous to the mitigation of drought risk. Then the drought risk distribution is obtained by the equation 1 (Figure.4f). The drought risk distribution approximates to the drought hazard distribution overall, and the subwatersheds with high drought risk distribute on the plain area of the middle watershed with higher drought hazard and bigger vulnerabilities.
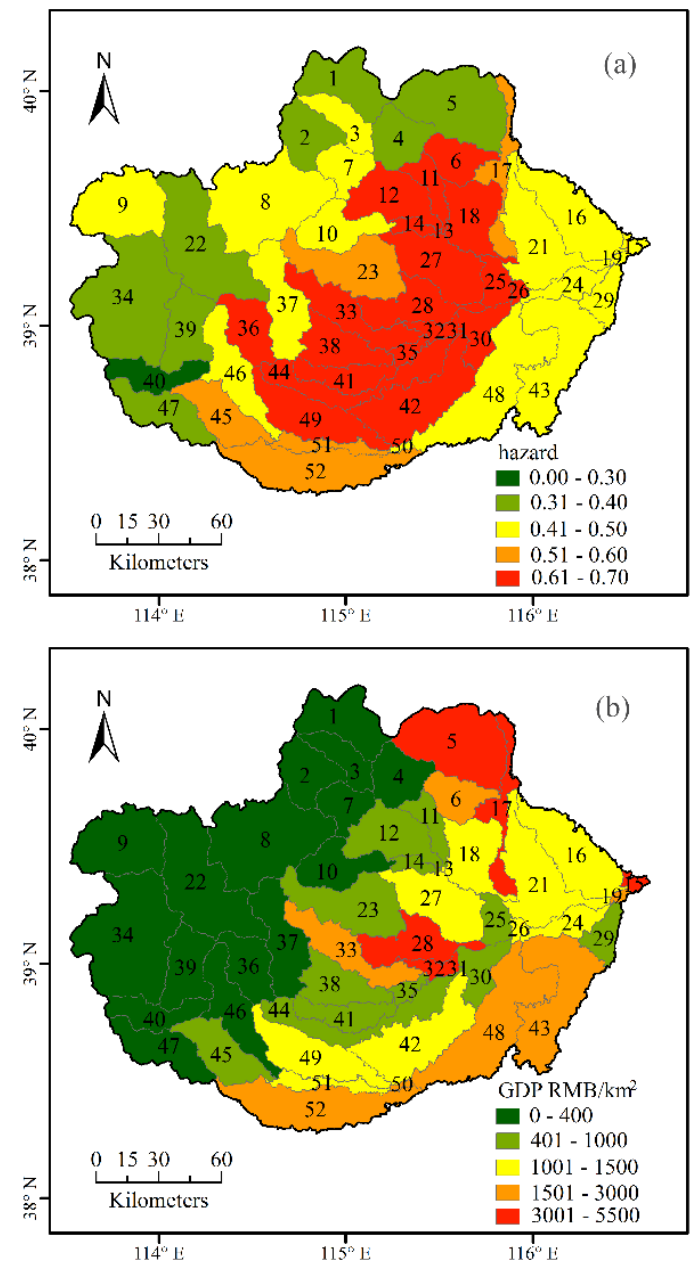

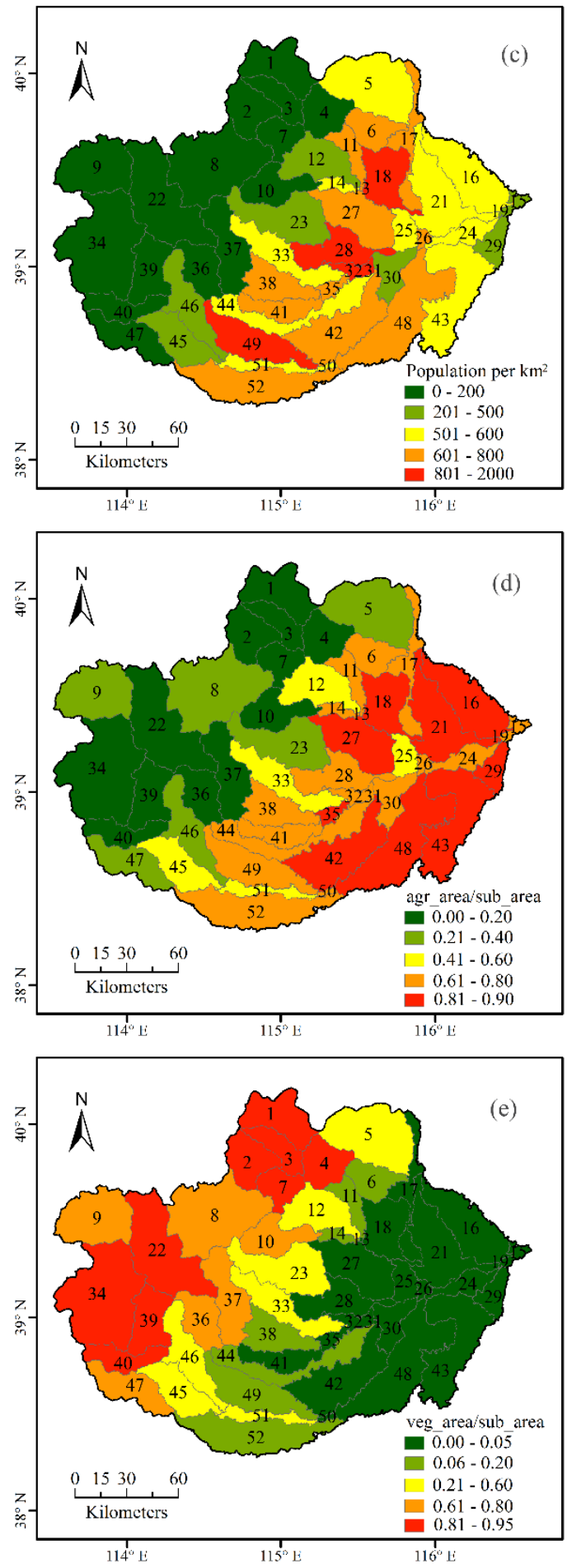

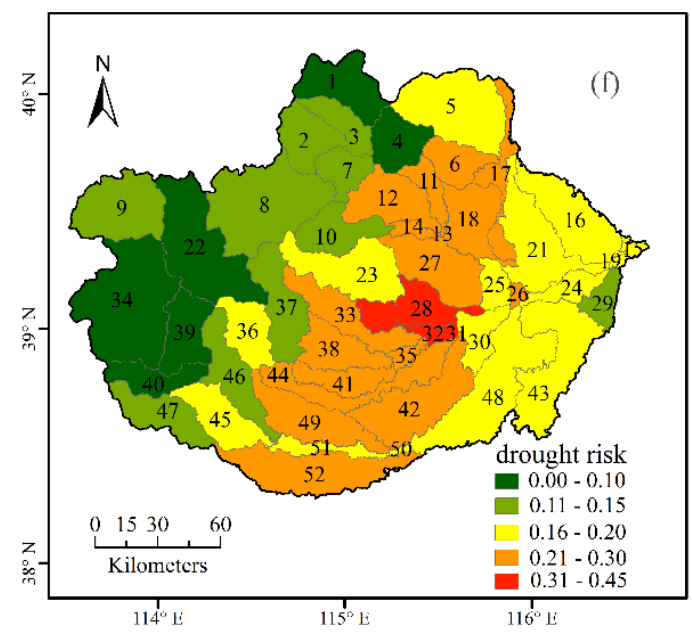

Figure.4 Distribution of the (a) drought hazard, exposed vulnerabilities: (b) GDP, (c) population, (d) ratio of cropland area to subwatershed area, (e) ratio of vegetation area to subwatershed area, and (f) drought risk.

\section{Conclusions}

PDSI is established and used in the Daqinghe watershed from 1991 to 2010, and PDSI is validated in comparison with the SPI, SRI, SMI, and agriculture drought-affect area in Baoding. The results show that PDSI is adequate to describe the drought hazard in the Daqinghe watershed, and the drought hazard concentrate in the downstream plain area of the watershed. Then, the exposed vulnerabilities consisting of population, GDP, cropland area, and vegetation area incorporate with the drought hazard to estimate the drought risk. The drought risk distribution agrees with the distribution of drought hazard since the closely approximate distribution of the population, GDP, cropland, and the drought hazard.

\section{Acknowledgments}

This study was supported by the National Key Research and Development Program of China (Grant No.2016YFC0401810), Independent research project of C.I.S.P.D.R. (CX2017Z03).

\section{References}

1. Bryant E. Natural hazards. Cambridge University Press, Camgridge UK (2005)

2. Maybank J, Bonsai B, Jones K, Lawford R, O'brien E, Ripley E, Wheaton E. Drought as a natural disaster. Atmosphere-Ocean 33, 195-222 (1995)

3. Sternberg T. Regional drought has a global impact. Nature 472, 169-169 (2011)

4. Türkeş M. Vulnerability of Turkey to desertification with respect to precipitation and aridity conditions. Turkish J Eng Env Sci, 23, 363-380 (1999)

5. Zhang D-D, Yan D-H, Lu F, Wang Y-C, Feng J. Copula-based risk assessment of drought in Yunnan province, China. Nat Hazards 75, 2199-2220 (2015) 
6. Li W-j, Tan Z, Lin L. Quantitative analysis of agrodrought impact on food security in China. Journal of Natural Disasters 19, 111-118 (2010)

7. Wang A, Zeng X. Sensitivities of terrestrial water cycle simulations to the variations of precipitation and air temperature in China. J Geophys Res 116, D02107 (2011)

8. Yan D, Weng B, Wang G, Wang H, Yin J, Bao S. Theoretical framework of generalized watershed drought risk evaluation and adaptive strategy based on water resources system. Nat Hazards 73, 259-276 (2014)

9. Zhai J, Su B, Krysanova V, Vetter T, Gao C, Jiang T. Spatial variation and trends in PDSI and SPI indices and their relation to streamflow in 10 large regions of China. J Climate 23, 649-663 (2010)

10. Mishra AK, Singh VP. A review of drought concepts. J Hydrol 391, 202-216 (2010)

11. Qin Y, Yang D, Lei H, Xu K, Xu X. Comparative analysis of drought based on precipitation and soil moisture indices in Haihe basin of North China during the period of 1960-2010. J Hydrol 526, 55-67 (2015)

12. Council A. AMS statement on meteorological drought. Bull Amer Meteor Soc 85, 771-773 (2004)

13. Dai A. Drought under global warming: a review. Wiley Interdisciplinary Reviews: Climate Change 2, 45-65 (2011)

14. Maia R, Vivas E, Serralheiro R, de Carvalho M. Socioeconomic evaluation of drought effects. Main principles and application to Guadiana and Algarve case studies. Water Resour Manag 29, 575-588 (2015)

15. Heim RR. Drought indices: a review. Drought: a global assessment, 159-167 (2000)

16. McKee TB, Doesken NJ, Kleist J The relationship of drought frequency and duration to time scales. In: Proceedings of the 8th Conference on Applied Climatology,. American Meteorological Society Boston, MA, 22, 179-183 (1993)

17. Shukla S, Wood AW. Use of a standardized runoff index for characterizing hydrologic drought. Geophys Res Lett 35, 226-236. L02405 (2008)

18. Hunt ED, Hubbard KG, Wilhite DA, Arkebauer TJ, Dutcher AL. The development and evaluation of a soil moisture index. Int J Climatol 29, 747-759 (2009)

19. Bonaccorso B, Peres DJ, Castano A, Cancelliere A. SPI-based probabilistic analysis of drought areal extent in Sicily. Water Resour Manag 29, 459-470 (2015)

20. Palmer WC. Meteorological drought vol 30. US Department of Commerce, Weather Bureau Washington, DC, USA (1965)

21. Jones P, Hulme M, Briffa K, Jones C, Mitchell J, Murphy J. Summer moisture availability over Europe in the Hadley centre general circulation model based on the Palmer drought severity index. Int J Climatol 16, 155-172 (1996)
22. López-Francos A. Drought management: scientific and technological innovations. Options Méditerranéennes Série A: Séminaires Méditerranéens (CIHEAM) a, 29-40 (2008)

23. Rao AR, Padmanabhan G. Analysis and modeling of Palmer's drought index series. J Hydrol 68, 211-229 (1984)

24. Johnson WK, Kohne RW. Susceptibility of reservoirs to drought using Palmer index. Journal of Water Resources Planning and Management 119, 367-387 (1993)

25. Kim T-W, Valdés JB. Nonlinear model for drought forecasting based on a conjunction of wavelet transforms and neural networks. Journal of Hydrologic Engineering 8, 319-328 (2003)

26. Wilhite DA, Svoboda MD, Hayes MJ. Understanding the complex impacts of drought: a key to enhancing drought mitigation and preparedness. Water Resour Manag 21, 763-774 (2007)

27. Liu S, Yan D, Wang J, Weng B, Wang G, Yang M. Drought Mitigation Ability Index and Application Based on Balance between Water Supply and Demand. WATER-SUI 7, 1792-1807 (2015)

28. Vicente-Serrano SM, Beguería S, López-Moreno JI. A multiscalar drought index sensitive to global warming: the standardized precipitation evapotranspiration index. J Climate 23, 1696-1718 (2010) 